\title{
Analysis of Gas Turbine Rotor Blade Tip and Shroud Heat Transfer
}

\author{
A.A. Ameri \\ AYT Corporation \\ Brook Park, Ohio \\ E. Steinthorsson \\ Institute for Computational Mechanics in Propulsion \\ Cleveland, Ohio
}

October 1996

Prepared for

Lewis Research Center

Under Cooperative Agreement NCC3-370

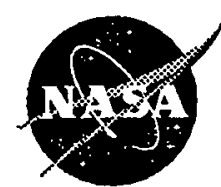

National Aeronautics and

Space Administration

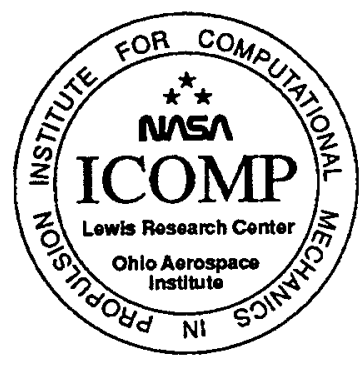




\title{
ANALYSIS OF GAS TURBINE ROTOR BLADE TIP AND SHROUD HEAT TRANSFER
}

\author{
A. A. Ameri \\ A.Y.T. Corporation, Brook Park, Ohio \\ E. Steinthorsson \\ Institute for Computational Mechanics in Propulsion (ICOMP) \\ NASA Lewis Research Center
}

\begin{abstract}

$\begin{array}{ll}\text { NOMENCLATURE } \\ \text { A } & \text { Flow area } \\ \mathrm{C}_{\mathbf{P}} & \text { Constant pressure specific heat } \\ \mathbf{k} & \text { Thermal conductivity } \\ \dot{m} & \text { Mass rate of flow } \\ \mathbf{N} & \text { Number of Blades } \\ \mathrm{Pr} & \text { Prandtl number } \\ \mathrm{St} & \text { Stanton number } \\ \mathrm{T} & \text { Temperature } \\ \mathrm{y}+ & \text { Dimensionless distance from the wall } \\ \text { Subscripts } \\ 1 & \text { Reference location } \\ \mathrm{n} & \text { Coordinate normal to the wall } \\ \mathrm{t} & \text { Total value at the stage inlet } \\ \mathrm{w} & \text { Wall condition }\end{array}$
\end{abstract}

Predictions of the rate of heat transfer to the tip and shroud of a gas turbine rotor blade are presented. The simulations are performed with a multiblock computer code which solves the Reynolds Averaged Navier-Stokes equations. The effect of inlet boundary layer thickness as well as rotation rate on the tip and shroud heat transfer is examined. The predictions of the blade tip and shroud heat transfer are in reasonable agreement with the experimental measurements. Areas of large heat transfer rates are identified and physical reasoning for the phenomena presented.

\section{INTRODUCTION}

The steady trend to raise the turbine inlet temperatures in modern gas turbine engines to attain high cycle efficiencies has elevated the problem of blade cooling to prominence. Of particular interest is the large thermal loads experienced by the rotor tips where the rate of heat transfer may be comparable to that of the stagnation line. Also, knowledge of shroud heat transfer can provide information leading to the design of cooling schemes useful in clearance gap control. In a recent paper, Ameri and Steinthorsson (1995) showed that the rate of heat transfer on the blade tip can be satisfactorily calculated using a Navier-stokes solver. The case chosen for that calculation was the Space Shuttle Main Engine (SSME) high pressure fuel side turbine. Use of correlations to predict the rate of heat transfer on the blade tip was found to be of limited use.

A brief review of work done in the area of identification of dominant flow and heat transfer mechanisms affecting the blade tip region was given in Ameri and Steinthorsson (1995). Much work has been done in the area of simulation of the flow field in the tip clearance region. The approach typically taken has been mostly to solve the three-dimensional flow field around the entire blade, including the tip gap region. In contrast, numerical calculation of tip heat transfer, with the exception of the work of the present authors cited above, is mainly limited to the use of empirical correlations involving starting length heat transfer or at most two-dimensional simulations on simplified geometries and boundary conditions.

In the area of shroud heat transfer measurements, the work of Dunn et al. (1984), Kumada et al. (1992) and Epstein et al. (1985) appear in the literature. Dunn and coworkers $(1984 a, 1984 b)$ measured the rate of heat transfer on the tip, along the mean camber line as well as along the shroud of the rotor blade of Garrett's TFE 731-2 engine. Kumada et. al. made measurements of heat transfer coefficient on the shroud surface of a turbocharger while Epstein et. al. measured time resolved and time averaged heat transfer on the shroud of a transonic high pressure turbine. Some of the conclusions listed by Epstein et al. are quite interesting and relevant to this work and will be discussed in the Results and Discussions section of this paper. 
In the present paper results of calculations of heat transfer coefficient on the tip and shroud will be presented. The rotor blade chosen for this study belongs to Garrett's TFE 731-2 engine design for which experimental measurements of Dunn et. al. referenced above, are available.

\section{COMPUTATIONAL METHOD}

The simulations performed in this study were done using a computer code called TRAF3D.MB (Steinthorsson et al. 1993). This code is a general purpose flow solver, designed for simulations of flows in complicated geometries. The code is based on the TRAF3D, an efficient computer code designed for simulations of steady flows in turbine cascades (Arnone et al. 1991). The TRAF3D.MB code employs the full compressible Navier-Stokes equations. To handle complex geometries, the code uses multiblock grid systems (i.e., non-overlapping "zoned" grids), but has the added capability of handling grids with noncontiguous grid lines across branch cuts. The TRAF3D.MB code was described in detail by Steinthorsson et al. (1993). Some aspects of the formulation used in the code are the same as those described by Arnone et al. (1991).

In the course of the present calculations it was found that sometimes the iteration process became unstable when very fine grid was used in the tip clearance. To remedy this problem the code was modified to enable communication of information among blocks after every stage of the Runge-Kutta smoothing process instead of after the last stage only.

\section{Boundary Conditions}

The types of boundary conditions encountered in solving the problem at hand are as follows:

1) Inlet: The inlet boundary condition for axially subsonic flows is treated by specifying the total inlet temperature and total inlet pressure as well as the inlet angle profiles. The outgoing Riemann invariant is extrapolated to the inlet from within. The total temperature and pressure profiles are determined to match the law of the wall for the specified hydrodynamic and thermal boundary layer thicknesses on the hub and/or shroud.

2) Exit: At the exit boundary, for the subsonic axial flow, the pressure is specified and all the other conditions are extrapolated from within. The pressure at the exit plane is computed by integration of the radial equilibrium equation with specified hub endwall pressure at the exit.

3) Walls: At the walls, the normal pressure gradient is set to zero, the temperature or the gradient of the temperature is specified, and the no-slip condition is enforced. The density and total energy are computed from the pressure and the temperature.

4) Periodic boundaries are computed as interior points.

5) Non-matching grid: This type of boundary condition, which occurs on the wake line and on the inner boundary of the $\mathrm{O}$-grid in the tip region, is set by linear interpolation of the primary variables of the phantom cells.

\section{Turbulence and Transition Models}

In the present study, the Baldwin and Lomax (1978) algebraic turbulence model is employed. This model is patterned after the Cebeci model (1974) but modified to obviate the need for finding the edge of the boundary layer. It is a two-layer algebraic eddy viscosity model. The inner layer, which is very important in the calculation of heat transfer, uses the Prandtl-Van Driest formulation. The thermal diffusivity is calculated by assuming constant turbulent Prandtl number.

The transition, as affected by the normal and unsteady wake passing processes on the blade, is modeled using the method described by Mayle (1991). The application of the turbulence and transition model to the three-dimensional turbine blade heat transfer is described in Ameri and Arnone (1994). In the tip region, the turbulence model is implemented separately for the tip and the shroud surfaces assuming fully turbulent flow. The latter choice is justified since the tip flow directly emanates from the free stream which is likely to be fully turbulent. It is also hypothesized that any potential for relaminarization in the tip clearance will not be realized due to the small residence time in the tip gap region. The shroud boundary layer is also likely to be turbulent due to the highly turbulent turbine environment.

\section{RESULTS AND DISCUSSIONS}

The case chosen for this study is the rotor blade of Garett's TFE 731-2 HP turbine. Dunn and coworkers have performed extensive vane and blade surface heat transfer measurements on this turbine. They also measured the rate of heat transfer on the tip along the mean camber line of the rotor blade as well as along the shroud. The shroud and tip measurements conducted for two clearance gap heights of $0.0381 \mathrm{~cm}$ and 0.0635 were considered. These two gap heights correspond to gap heights of $1.11 \%$ and $1.85 \%$ of span at the location of the blade leading edge at the hub. Data for the shroud heat transfer for a third gap height of $0.0889 \mathrm{~cm}$ is also available but was not used in this study.

The flow conditions used in the present simulations are as given in Table 1 . The last two entries in the table are directly measured from the experiment while the remaining entries were obtained by analysis of the turbine stage using the MTSB code (Katsanis and McNally, 1977).

\begin{tabular}{|l|l|}
\hline $\begin{array}{l}\text { Absolute pressure Ratio across } \\
\text { the Blade Row }\end{array}$ & 0.64 \\
\hline Absolute Inlet Angle & $70^{\circ} \mathrm{Hub}$ \\
& $68^{\circ} \mathrm{Mid}$ Span \\
& $65^{\circ}$ Shroud \\
\hline Rotation Rate & $19,500 \mathrm{RPM}$ \\
\hline $\mathrm{T}_{\mathrm{w}} / \mathrm{T}_{\mathrm{t}}$ & 0.55 \\
\hline
\end{tabular}

TABLE 1. Conditions used in simulation of the rotor flow

An important difference between the geometry used in the computations and the TFE 731-2 used by Dunn and coworkers is that TFE 731-2 possesses a recess in the shroud (see fig. 1). It is clear that this recess can cause differences in the flow patterns 
over the tip, in particular near the leading edge of the blade tip. The specific details about the geometry of the recess is unknown. Nonetheless, if the inflow angles and boundary layer thickness at the inflow are carefully selected (see discussion below), the experimental data is useful to gauge the validity of the computed solutions as the level of heat transfer should be comparable.

\section{Grid System}

The calculations are performed using a grid system with five blocks. Three of the blocks, shown in Figure 2, are $\mathrm{C}$ grids that wrap around the turbine blade. The fourth block, shown in Figure 3 , is of the $O$ type and covers the tip clearance. Block 5 shown in Figure 3, is of $H$ type. It covers the entire span and is used to specify the inlet boundary condition. The C-grid is generated by using an elliptic scheme to construct an "inviscid" grid and the viscous grid is made by embedding grid lines in the vicinity of the no-slip boundaries with the desired wall spacing. The hub to tip grid is constructed by radial stacking of the $\mathrm{C}$ grid. This is done using geometric stretching. The first grid lines parallel to the hub or the shroud endwall are constructed to lie within the viscous sublayer.

The $\mathrm{O}$-grid used for the tip clearance is generated algebraically. The transverse grid lines span the distance between the mean camber line and the corresponding grid node on the $\mathrm{C}$ grid. The tip $O$ grid is refined close to the edge of the blade to allow for the large variations in the flow in that region. The $\mathbf{O}$-grid is also stacked in the spanwise direction using geometric stretching.

Tables 2 and 3 list the grid dimensions used in this study. The grid density on the blade surface is held constant while the tip and shroud region grid is refined in the radial direction. It was found as reported in a previous paper (Ameri and Steinthorsson 1995) that the solution on the tip is relatively insensitive to the grid resolution on the blade. Nevertheless, the grid covering the blade is quite fine and is judged to be adequate for the present computations.

All the grids are constructed such that the distance of the cell centers adjacent to solid walls, in wall units $\left(\mathrm{y}^{+}\right)$is close to unity. For grid lines adjacent to the hub endwall, this rule is relaxed to avoid large grid stretching ratios. Values of $y^{+} \sim 10$ are generated in that region.

\section{Heat Transfer}

All heat transfer results presented in this paper are given in terms of Stanton number defined as:

$$
S t=\frac{-k \partial T /\left.\partial n\right|_{w}}{(\dot{m} / A)_{1} C_{p}\left(T_{w}-T_{t}\right)}
$$

Shroud heat transfer is in reality unsteady. In the experimental measurements used here the time dependence was removed by presenting average value of heat transfer on the shroud as a function of distance along the axis of the turbine. To obtain equivalent values of shroud heat transfer rate from the present steady computations, the local variation of heat transfer was circumferentially area averaged. Figure 4 is a snapshot of the

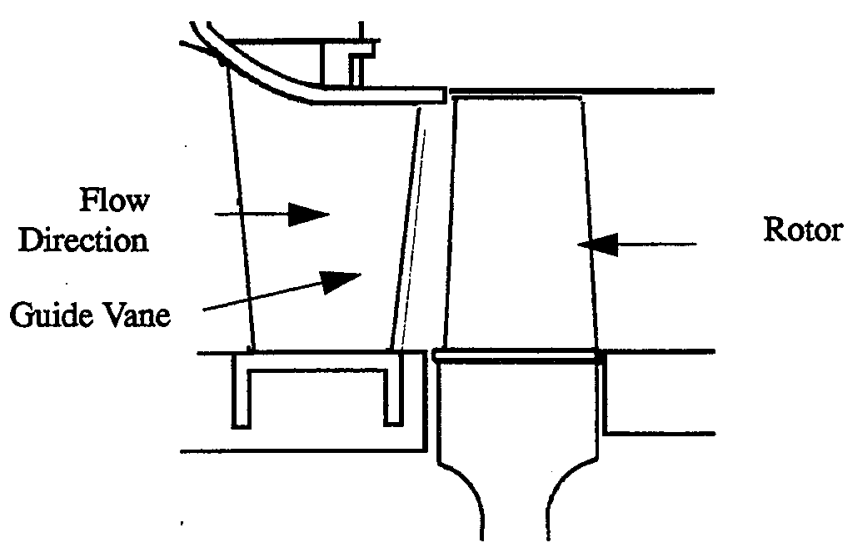

Fig. 1 Sketch of the geometry.

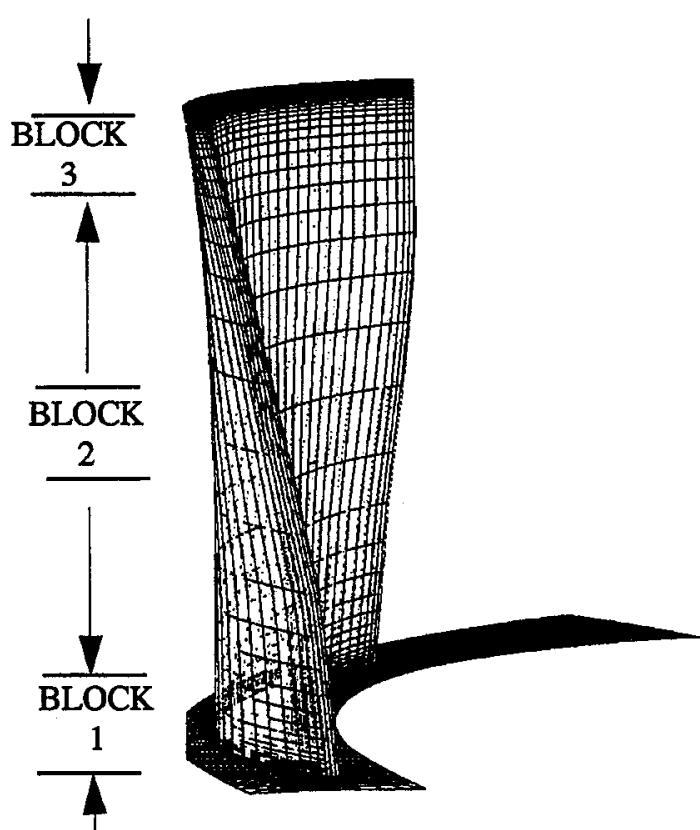

Fig. 2 TFE731-2 Blade and the blade C grid.

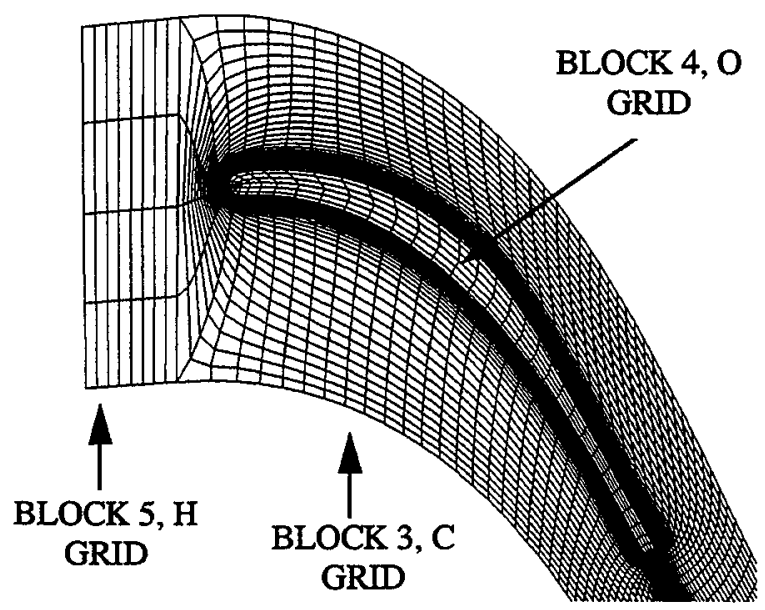

Fig. 3 Juxtaposition of the O-grid in the tip block, blade C grid and the inlet $\mathrm{H}$ grid. Every other grid line in the blade circumferential direction has been omitted for clarity. 


\begin{tabular}{|l|l|}
\hline & \multicolumn{1}{|c|}{$\begin{array}{c}\text { Grid Cell } \\
\text { Dimensions }\end{array}$} \\
\hline Circumferential & 192 \\
\hline Transverse & 48 \\
\hline Spanwise, hub to Tip & 64 \\
\hline Spanwise, tip to shroud & $20 / 32 / 40$ \\
\hline
\end{tabular}

TABLE 2. C-grid dimensions.

\begin{tabular}{|l|l|}
\hline & \multicolumn{1}{|c|}{$\begin{array}{c}\text { Grid Cell } \\
\text { Dimensions }\end{array}$} \\
\hline Circumferential & 128 \\
\hline Transverse & 16 \\
\hline Spanwise, tip to shroud & $20 / 32 / 40$ \\
\hline
\end{tabular}

TABLE 3. O-grid dimensions.

distribution of heat transfer on the shroud. The average rate of heat transfer at a given axial distance can be computed using the following formula:

$$
S t_{x}=\frac{\sum S t_{i} \Delta \theta}{2 \frac{\pi}{N}}
$$

where $S t_{i}$ is the interpolated local value of Stanton number at the intersection of a constant $x$ line and a grid line and $\Delta \theta$ is the circular arc angle for which that value of Stanton number is assumed to be prevalent. Any unsteady contribution to heat transfer on the shroud will not be accounted for due to the steady nature of computations.

Effect of Inlet Boundary Laver Thickness and Rotation Rate. As mentioned previously, the inflow boundary conditions, such as flow angle, total pressure and total temperature were determined from a simplified stage analysis. The actual incoming flow is not uniform and contains vortical structures generated due to the presence of the upstream vanes. In addition the incorrivis flow is unsteady due to the presence of wakes and the roturion sif the blades. True reproduction of the inlet profile, can not be accomplished without a complete unsteady stage calculation. The boundary layer thickness was varied in an attempt to produce the best agreement with the experimental measurements of tip and shroud heat transfer.

Figure 5 shows the effect of the shroud inlet boundary layer thickness on the heat transfer on the blade tip and the shroud. All the results presented in that figure were obtained with an RPM= $17500,92 \%$ of nominal value. In that figure (and all the line plots

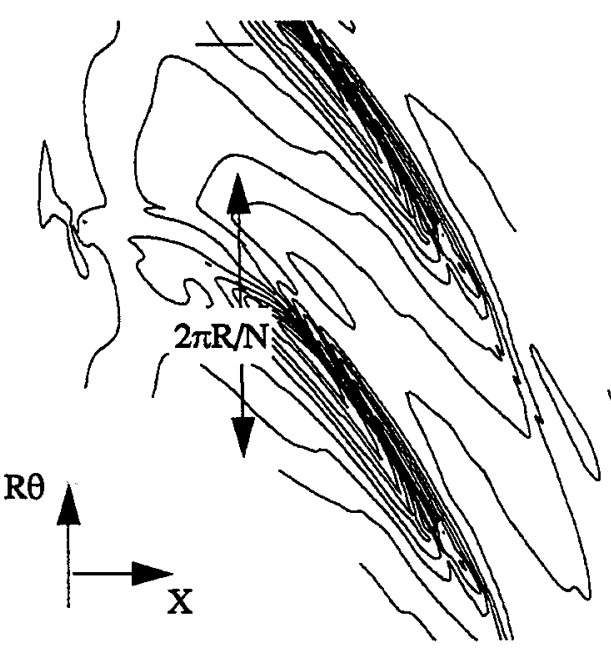

Fig. 4 Typical Stanton number distribution on the shroud and nomenclature used to calculate average shroud heat transfer.

to follow) heavy lines designate the average shroud heat transfer while light lines designate tip mean camber heat transfer.

Initially, the inlet boundary was placed at $60 \%$ of axial chord upstream of the blade leading edge. As expected a thinner boundary layer resulted in a larger rate of heat transfer. However even with very thin boundary layer the shroud heat transfer rate was much lower than that suggested by experimental measurements (shown in Figure 6). Subsequently, it was decided to place the inlet boundary at $30 \%$ of axial chord upstream of the leading edge with $0.1 \%$ inlet boundary layer thickness. This is justified on the grounds that in the experiment the spacing between the upstream guide vanes and the blade row is quite small ( $<30 \%$ of axial chord). The rate of heat transfer on the tip and the shroud (shown with chained lines) increased markedly in better agreement with the data.

With the inlet boundary located as determined above, the effect of rotation rate on the heat transfer was determined. Note that the rotation velocity at the tip of the this blade is larger than the absolute tangential velocity for both rotation rates considered. Therefore, increasing the rotation rate in this particular design increases the relative velocity and thus increases the inlet relative flow velocity in the shroud region. Note also that there was no appreciable change in the rate of mass flow through the turbine and thus a change in the Stanton number directly translates into a change in the rate of heat transfer (cf. eq. 1). The lines of Figure 6 suggest that the rate of heat transfer increases slightly in the leading edge region of the blade on the tip while the effect of increasing of the blade rotation rate on the shroud heat transfer is minimal. This observation agrees with intuition as well as experimental observations of Epstein at. al. (1985). The increase in the tip heat transfer could be due to the increase in the incoming relative flow velocity. The shroud heat transfer however is not 


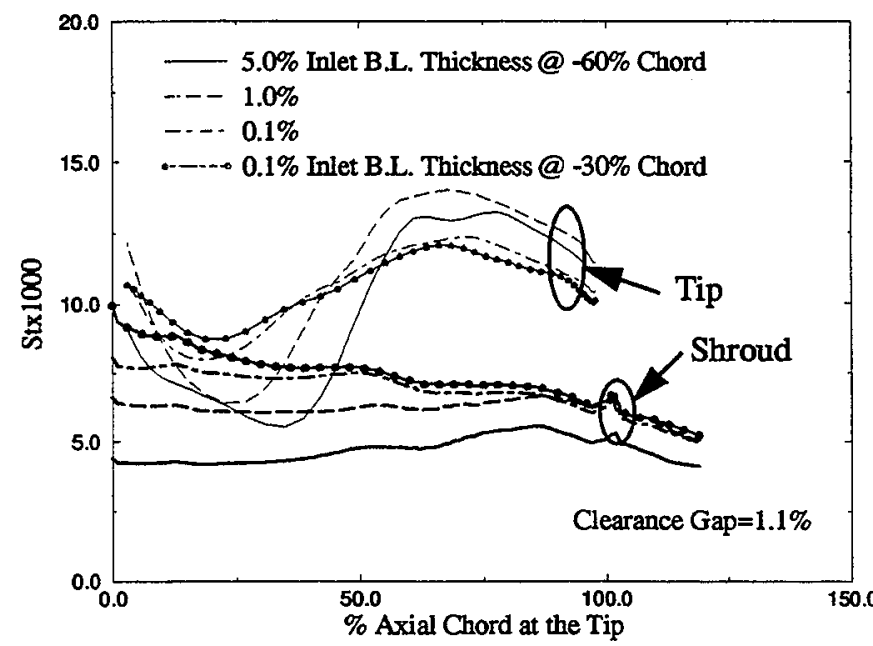

Fig. 5 Typical effect of inlet boundary layer thickness on the heat transfer at the tip mean camber line.

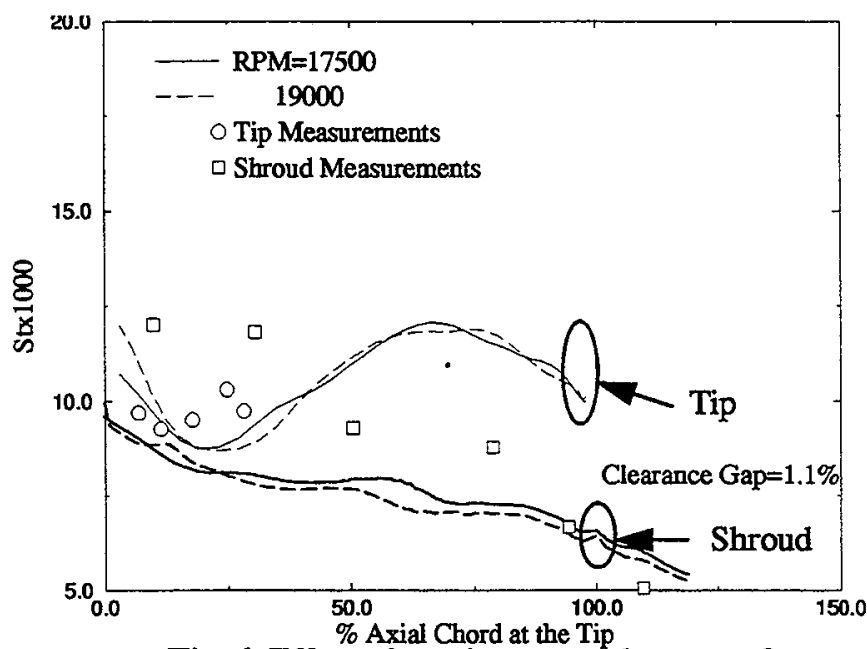

Fig. 6 Effect of rotation rate on heat transfer.

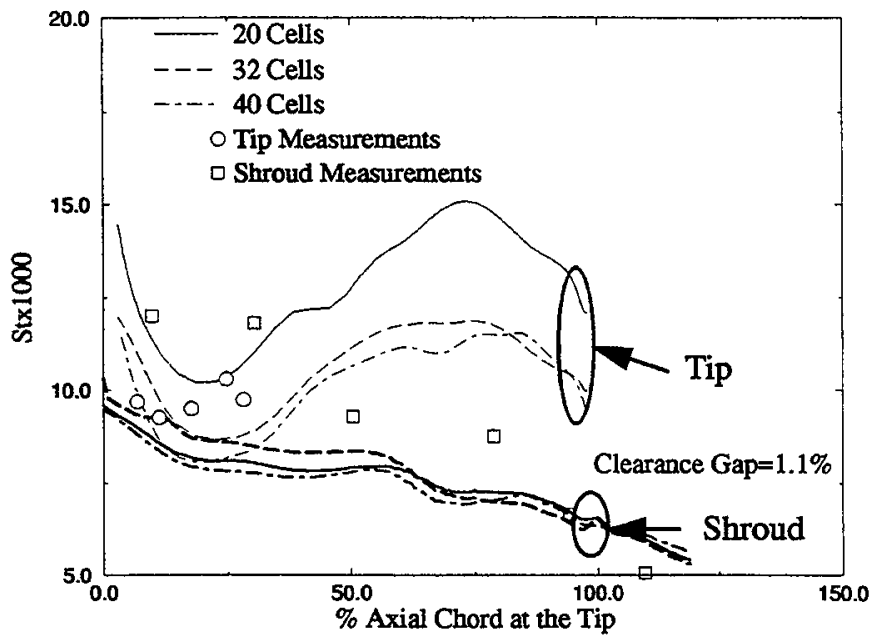

Fig. 7 Effect of grid density on the predicted heat transfer on the tip mean camber line and the averaged shroud heat transfer. changed very much since the heat transfer on the shroud is dependent on the absolute flow velocity which remained unchanged.

Tip and Shroud Heat Transfer Results. The first question to address when computing the shroud and tip heat transfer is the question of adequate grid resolution. Figure 7 presents the results of simulations with 20,32 and 40 cells in the radial direction in the tip clearance. Calculations with 32 and 40 cells had the same wall spacing $\left(\mathrm{y}^{+} \sim 1\right.$.), whereas the coarsest grid had a larger spacing from the wall to maintain reasonable stretching ratio. The tip heat transfer appears to be more sensitive to the grid resolution than the shroud. There is a large difference in the predicted tip heat transfer between 20 and 32 cells and a smaller difference between 32 and 40 cells. Figure 7 suggests that the successful prediction of tip heat transfer requires extra fine resolution of at least as many as 40 cells in the small clearance region. However, as can be seen from Figure 8 , when seen as whole, the results of 32 and 40 cells are quite similar. Possible reasons for the departure of the present heat transfer results from the experimental measurements are discussed at the end of this section.

Results presented in Figure 8 show some interesting patterns. For example the rate of heat transfer at the leading edge of the tip and along the edge on the suction side of the blade appears to be quite high. To understand why the heat transfer is high in this region, it is necessary to study the flow field near the tip. Figure 9(a) shows the trace of the reattachment line on the tip surface. To the left of the figure, trace of the flow across the blade at locations marked as A and B are also shown. Location A corresponds to the leading edge region while location $B$ is in the downstream region. Referring to Figures 9(b) and (c), lip separation and subsequent reattachment can be discerned. Typically, flow reattachment is recognized as the mechanism for enhancement of heat transfer on the tip (Mayle and Metzger, 1982 and Metzger et. al. 1989). The increase in heat transfer is due to rejuvenation of the boundary later after reattachment coupled with the high gas temperature in the free stream. Indeed, referring to Figure 9(d), the free stream flow in the leading edge region of the tip originates from upstream of the rotor where it is at elevated temperatures. At locations on the pressure side of the tip, the flow has had a chance to cool, having come from the pressure surface of the blade. Thus the expected increase in the rate of heat transfer due to reattachment does not materialize.

The large rate of heat transfer along the suction side edge is attributable to the thinning of the boundary layer in that region due to the presence of a large favorable pressure gradient (declining pressure in the direction of the flow) as evidenced by Figures 10(a) and (b). An increase in the rate heat transfer due to the presence of such "sink" flows has been discussed by Metzger and Rued (1989) in connection with the blade pressure side heat transfer near the tip, however the same mechanism applies to the present problem.

Figure 12 shows the heat transfer pattern on the shroud of the rotor. Although the average rate of heat transfer in the axial direction is declining as seen in Figure 7, (in agreement with the observations of Epstein et. al., (1985) and Dunn et. al. (1984)) the local heat transfer rate is seen to be quite larger in the mid-chord 


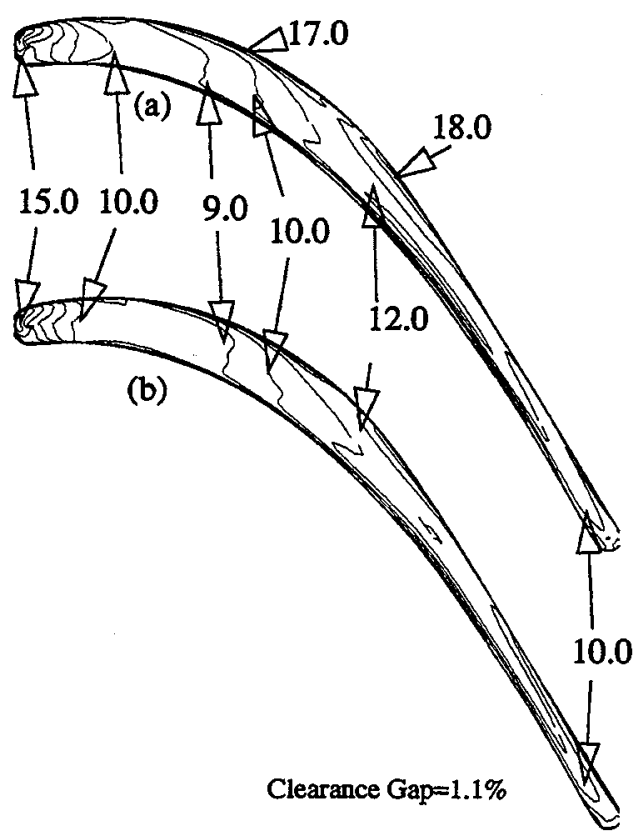

Fig. 8 Effect of grid density on the predicted tip heat transfer(Stx1000). (a) 32 and (b) 40 radial cells in the tip Clearance.
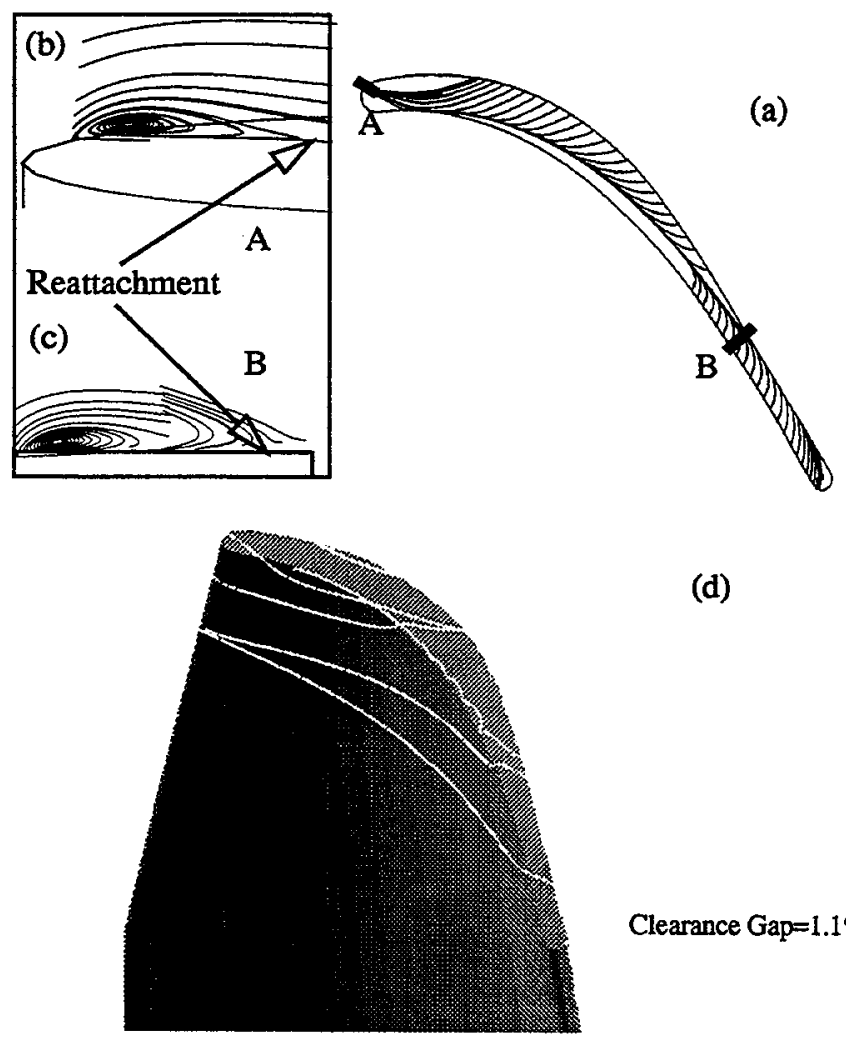

(d)

Clearance Gap $=1.1 \%$

Fig. 9 (a)- Oil flow trace on the blade tip, showing the reattachment line. (b)- Selected cuts across the blade tip showing the tip vortex. (c) Trace of the flow over the tip showing the tip vortex.

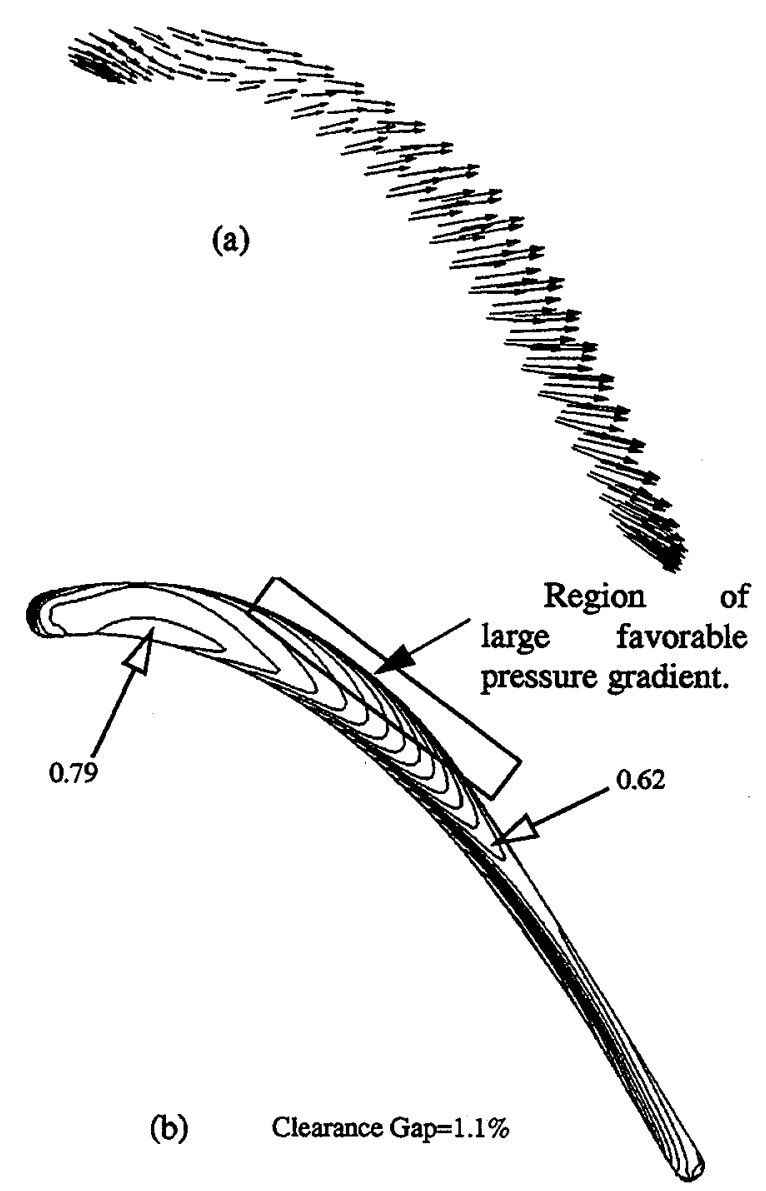

Fig. 10 (a)-Velocity vectors in the mid gap height of the tip clearance. (b)- Tip pressure distribution showing areas of large pressure gradient.

region of the shroud. Figure 11 shows the contours of pressure on the shroud. The location of the occurrence of large heat transfer rate corresponds to a region of large favorable pressure gradient (sink flow). Such sink flow was also observed and reported by Epstein et. al.

The results of predictions with the larger gap size of $1.8 \%$ are shown in Figures 13 and 14. Again the results of grid independence study suggest reasonable grid convergence. Agreement with the experimental data for the shroud results is quite good. The tip heat transfer predictions with the exception of the data point at $7 \%$ of the chord agree well with the experimental data. The cause of the discrepancy can be attributed to the effect of the shroud recess. Figure 14 shows the Stanton number results for the entire tip. Again as in the smaller gap size, regions with large heat transfer rates appear to exist close to the leading edge and along the edge on the suction side of the tip surface. Comparing the tip heat transfer plots for the two gap sizes of $1.1 \%$ and $1.8 \%$, the general decline in levels with increasing the gap size is quite evident.

Lastly, the reader is reminded that for the present calculations, close agreement with experimental results should not be expected due to the following two factors. The first 


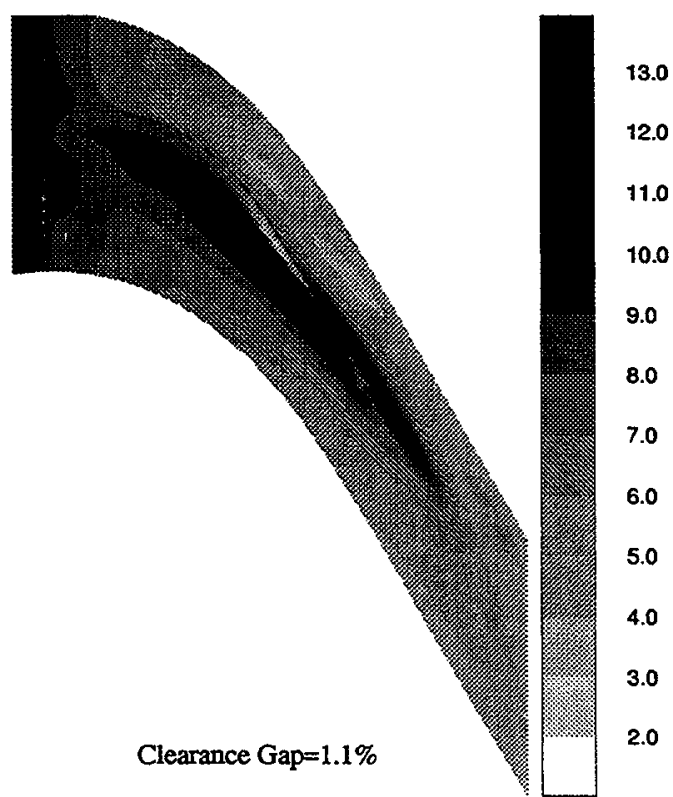

Fig. 11 Shroud heat transfer(Stx1000).

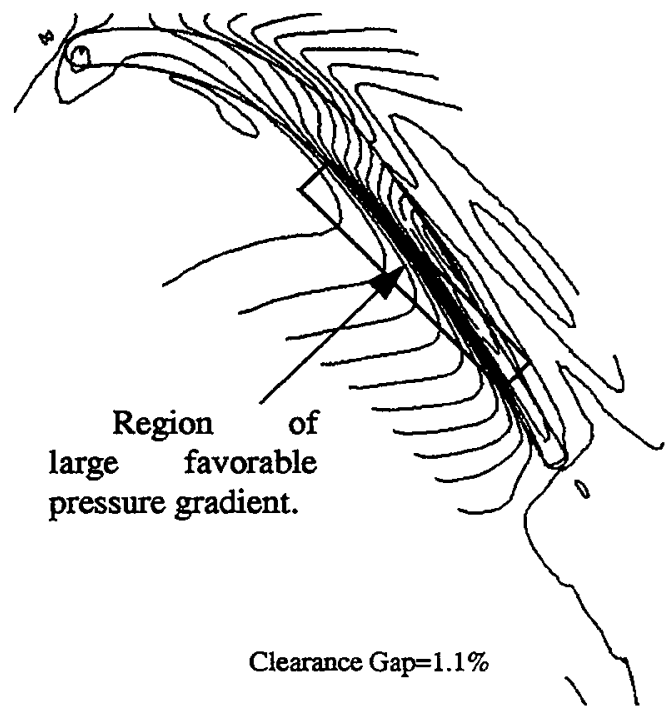

Fig. 12 Shroud pressure distribution showing areas of large pressure gradient.

factor is the difference between the simulated and the real inlet boundary conditions. The simulated inlet is free from vortical structures, wakes and the associated unsteadiness that characterize the true turbine environment. The second factor is the presence of the shroud in the experimental hardware which is not modeled in this work. The presence of the recess can have effects ranging from separation of the flow on the shroud (as in a backward facing step) to modification of the suction side vortex which in turn can have large effects on the tip and shroud heat transfer. The present calculations exhibit improved agreement with the experimental measurements for the larger gap size. This can be attributed to the diminishing effect of the recess with increasing gap size.

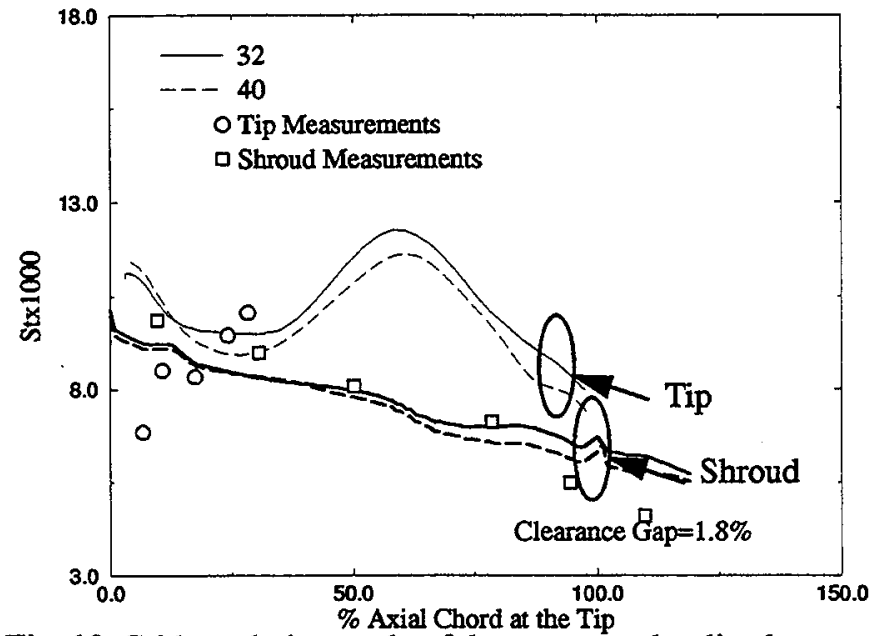

Fig. 13 Grid resolution study of the mean camber line heat transfer on the tip surface.

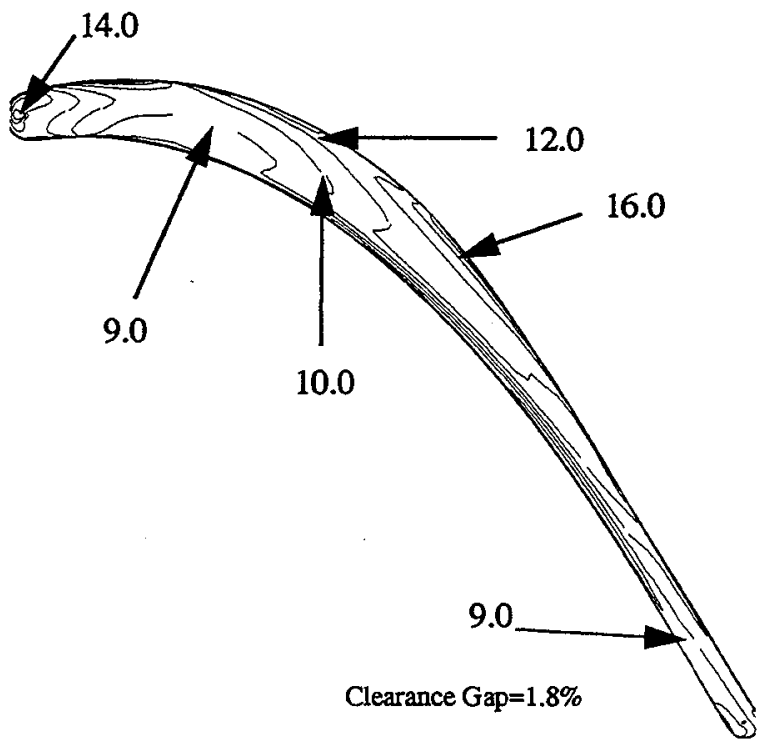

Fig. 14 Heat transfer distribution on the blade tip (Stx1000).

Improving agreement with the experimental results on the shroud away from the leading edge of the blade is another evidence of the effect of the recess. Unfortunately, all the measurements of the blade tip heat transfer are limited to $40 \%$ chord length of the blade, and no comparison can be made in that region.

\section{SUMMARY AND CONCLUSIONS}

In this work the heat transfer to the blade tip and the shroud of a gas turbine rotor was simulated. A multi-block NavierStokes code was used. The domain of computations was descretized using a 5 block grid system. The case considered for 
the calculations was the TFE 731-2 high pressure turbine of Garrett. Two regions of large heat transfer on the tip were identified. One region was close to the leading edge and the second along the suction side of the tip surface. The mechanism of the enhancement were identified as reattachment and existence of sink flow respectively. The average shroud heat transfer was seen to decrease monotonically with increasing distance along the axial flow direction. Locally large rates of heat transfer on the shroud was observed above the blade and on the pressure side. The existence of the large peak of heat transfer was attributed to the steep favorable pressure gradient at that location.

\section{ACKNOWLEDGEMENT}

The authors wish to express their gratitude to Dr. Michael Dunn of Calspan for providing the experimental data, and Kaz Civinskas for sharing the MTSB analysis. Thanks are also due to Dr. Raymond Gaugler Chief of the Turbomachinery Flow Physics Branch, as well as to Dr. Louis Povinelli Chief of the Internal Fluid Mechanics Division of NASA Lewis Research Center and director of ICOMP for their support and encouragement of this work.

\section{REFERENCES}

Ameri, Ali A., E. Steinthorrson, 1995, "Prediction of Unshrouded Rotor Blade Tip Heat Transfer," ASME 95-GT-142.

Ameri, Ali A., Amone, A., 1994, "Transition Modeling Effects on Turbine Rotor Blade Heat Transfer Predictions," ASME 94-GT-22. To be published in the Journal of Turbomachinery.

Arnone, A., Liou, M. S., and Povinelli, L. A., 1992, "NavierStokes Solutions of Transonic Cascade Flows Using NonPeriodic C Type Grid," AlAA Journal of Propulsion and Power, Vol. 8, No.2, pp. 410-417.

Baldwin, B. S. and Lomax, H., 1978, "Thin Layer Approximation and Algebraic Model for Separated Turbulent Flows," AIAA paper 78-0257.

Cebeci, T., Smith, A. M. O. 1974,"Analysis of Turbulent Boundary Layers," Academic Press, N.Y.

Dunn, M.G., Rae, W. J. and Holt, J. L. 1984a, "TimeMeasurement and Analyses of Heat Flux Data in a Turbine Stage: Part I- Description of Experimental Apparatus and Data Analysis," ASME Transactions, Journal of Turbomachinery, Vol. 106, No.1, pp. 229-233.

Dunn, M.G., Rae, W. J. and Holt, J. L. 1984b, "TimeMeasurement and Analyses of Heat Flux Data in a Turbine Stage: Part II- Discussion of Results and Comparison With Predictions," ASME Transactions, Journal of Turbomachinery, Vol. 106, No.1, pp. 234-240.

Epstein, A. H. and Guenette, G. R., Norton, R. J. G. and Yuzhang, C., 1985, "Time Resolved Measurements of a Turbine Rotor Stationary Tip Casing Pressure \& Heat Transfer Field," AIAA paper No. 85-1220.

Kumada, M., Iwata, S., Obata M. and Watanabe, O., 1994, "Tip Clearance Effect on Heat Transfer and Leakage Flows on the Shroud-Wall Surface in An Axial Flow Turbine," ASME
Transactions, Journal of Turbomachinery, Vol. 116, No.1, pp. 3945.

Katsanis, T. and McNally, W. D., 1977, "Revised FORTRAN Program for Calculating Velocities and Streamlines on the Hub-Shroud Mid-Channel Stream Surface of an Axial, Radial, or Mixed Flow Turbomachine or Annular Duct," Vol. I, User's Manual, Vol. II, Programmer's Manual, NASA TN D8430, 8431.

Mayle, R. E., 1991, "The Role of Laminar-Turbulent Transition in Gas Turbine Engines," ASME Journal of Turbomachinery, Vol. 113, pp. 509-537.

Mayle, R. E. and Metzger, D. E., 1982, "Heat Transfer at the Tip of Unshrouded Turbine Blade," Proceedings of the 7th International Heat Transfer Conference, Vol 3, 1982, pp. 87-92.

Metzger, D. E., Bunker, R. S. and Chyu, M. K., 1989, "Cavity Heat Transfer on a Transverse Grooved Wall in a Narrow Channel", Journal of Heat Transfer, Vol. 111, pp. 73-79.,

Metzger, D. E. and Rued, K., 1989, "The Infiuence of Turbine Clearance Gap Leakage on Passage Velocity and Heat Transfer Near Blade Tips: Part I- Sink Flow Effects on Blade Pressure Side," ASME Transactions, Journal of Turbomachinery, Vol. 111, pp. 284-292.

Steinthorsson, E., Liou, M. S., and Povinelli, L.A., 1993, "Development of an Explicit Multiblock/Multigrid Flow Solver for Viscous Flows in Complex Geometries," AIAA-93-2380. 

Public reporting burden for this collection of information is estimated to average 1 hour per response, inclucing the time for reviewing instructions, searching existing data sources, gathering and maintaining the data needed, and completing and reviewing the collection of information. Send comments regarding this burden estimate or any other aspect of this collection of information, including suggestions for reducing this burden, to Washington Headquanters Services, Directorate for Intormation Operations and Reports. 1215 Jefters
1. AGENCY USE ONLY (Leave blank)
2. REPORT DATE
October 1996
3. REPORT TYPE AND DATES COVERED
Contractor Report

4. TITLE AND SUBTITLE 5. FUNDING NUMBERS

Analysis of Gas Turbine Rotor Blade Tip and Shroud Heat Transfer

6. AUTHOR(S)

WU-505-90-5K

NCC3-370

A.A. Ameri and E. Steinthorsson

7. PERFORMING ORGANIZATION NAME(S) AND ADDRESS(ES)

8. PERFORMING ORGANIZATION REPORT NUMBER

Institute for Computational Mechanics in Propulsion 22800 Cedar Point Road

E-10491

Cleveland, Ohio 44142

10. SPONSORING/MONITORING

9. SPONSORING/MONITORING AGENCY NAME(S) AND ADDRESS(ES) AGENCY REPORT NUMBER

National Aeronautics and Space Administration

Lewis Research Center

Cleveland, Ohio 44135-3191

NASA CR-198541

ICOMP-96-9

96-GT-189

11. SUPPLEMENTARY NOTES

Prepared for the 41st Gas Turbine and Aeroengine Congress sponsored by the International Gas Turbine Institute of the American Society of Mechanical Engineers, Birmingham, United Kingdom, June 10-13, 1996. A.A. Ameri, AYT Corporation, Brook Park, Ohio; and E. Steinthorsson, Institute for Computational Mechanics in Propulsion, NASA Lewis Research Center (work funded under NASA Cooperative Agreement NCC3-370) . ICOMP Program Director, Louis A. Povinelli, organization code 2600, (216) 433-5818.

12a. DISTRIBUTIONAVAILABILITY STATEMENT 12b. DISTRIBUTION CODE

Unclassified - Unlimited

Subject Category 34

This publication is available from the NASA Center for AeroSpace Information, (301) 621-0390.

13. ABSTRACT (Maximum 200 words)

Predictions of the rate of heat transfer to the tip and shroud of a gas turbine rotor blade are presented. The simulations are performed with a multiblock computer code which solves the Reynolds Averaged Navier-Stokes equations. The effect of inlet boundary layer thickness as well as rotation rate on the tip and shroud heat transfer is examined. The predictions of the blade tip and shroud heat transfer are in reasonable agreement with the experimental measurements. Areas of large heat transfer rates are identified and physical reasoning for the phenomena presented.

14. SUBJECT TERMS

Computational fluid dynamics; Gas turbine heat transfer; Blade-tip

\begin{tabular}{|c|c|}
\hline $\begin{array}{c}\text { 17. SECURITY CLASSIFICATION } \\
\text { OF REPORT }\end{array}$ & $\begin{array}{c}\text { 18. SECURTY CLASSIFICATION } \\
\text { OF THIS PAGE } \\
\text { Unclassified }\end{array}$ \\
Unclassified \\
\hline
\end{tabular}

19. SECURITY CLASSIFICATION OF ABSTRACT Unclassified 